\title{
Canagliflozin Inhibits Human Endothelial Cell Proliferation and Tube Formation
}

\section{OPEN ACCESS}

Edited by:

Nicolau Beckmann, Novartis Institutes for BioMedical Research, Switzerland

Reviewed by: Carlos F. Sánchez-Ferrer, Autonomous University of Madrid,

Spain

Carlos Alonso Escudero, University of the Bío Bío, Chile

Nina Claudia Weber,

University of Amsterdam, Netherlands

${ }^{*}$ Correspondence: William Durante durantew@health.missouri.edu

Specialty section: This article was submitted to Cardiovascular and Smooth Muscle Pharmacology,

a section of the journal Frontiers in Pharmacology

Received: 17 December 2018 Accepted: 22 March 2019 Published: 16 April 2019

Citation: Behnammanesh G, Durante ZE, Peyton KJ, Martinez-Lemus LA,

Brown SM, Bender SB and Durante W (2019) Canagliflozin Inhibits Human Endothelial Cell Proliferation and Tube Formation. Front. Pharmacol. 10:362. doi: 10.3389/fphar.2019.00362

\author{
Ghazaleh Behnammanesh', Zane E. Durante', Kelly J. Peyton', Luis A. Martinez-Lemus ${ }^{1,2}$, \\ Scott M. Brown ${ }^{3,4}$, Shawn B. Bender ${ }^{2,3,4}$ and William Durante ${ }^{1 *}$ \\ ${ }^{1}$ Department of Medical Pharmacology and Physiology, School of Medicine, University of Missouri, Columbia, MO, \\ United States, ${ }^{2}$ Dalton Cardiovascular Research Center, University of Missouri, Columbia, MO, United States, ${ }^{3}$ Research \\ Service, Harry S. Truman Memorial Veterans Hospital, Columbia, MO, United States, ${ }^{4}$ Biomedical Sciences, University of \\ Missouri, Columbia, MO, United States
}

Recent clinical trials revealed that sodium-glucose co-transporter 2 (SGLT2) inhibitors significantly reduce cardiovascular events in type 2 diabetic patients, however, canagliflozin increased limb amputations, an effect not seen with other SGLT2 inhibitors. Since endothelial cell (EC) dysfunction promotes diabetes-associated vascular disease and limb ischemia, we hypothesized that canagliflozin, but not other SGLT2 inhibitors, impairs EC proliferation, migration, and angiogenesis. Treatment of human umbilical vein ECs (HUVECs) with clinically relevant concentrations of canagliflozin, but not empagliflozin or dapagliflozin, inhibited cell proliferation. In particular, $10 \mu \mathrm{M}$ canagliflozin reduced EC proliferation by approximately $45 \%$. The inhibition of EC growth by canagliflozin occurred in the absence of cell death and was associated with diminished DNA synthesis, cell cycle arrest, and a striking decrease in cyclin A expression. Restoration of cyclin A expression via adenoviral-mediated gene transfer partially rescued the proliferative response of HUVECs treated with canagliflozin. A high concentration of canagliflozin ( $50 \mu \mathrm{M})$ modestly inhibited HUVEC migration by $20 \%$, but markedly attenuated their tube formation by $65 \%$ and EC sprouting from mouse aortas by $80 \%$. A moderate $20 \%$ reduction in HUVEC migration was also observed with a high concentration of empagliflozin $(50 \mu \mathrm{M})$, while neither empagliflozin nor dapagliflozin affected tube formation by HUVECs. The present study identified canagliflozin as a robust inhibitor of human EC proliferation and tube formation. The anti-proliferative action of canagliflozin occurs in the absence of cell death and is due, in part, to the blockade of cyclin A expression. Notably, these actions are not seen with empagliflozin or dapagliflozin. The ability of canagliflozin to exert these pleiotropic effects on ECs may contribute to the clinical actions of this drug.

\section{Keywords: canagliflozin, endothelial cells, proliferation, migration, tube formation}

\section{INTRODUCTION}

Cardiovascular disease is the primary cause of morbidity and mortality in diabetes. Individuals with diabetes have a two- to four-fold increased rate of death due to cardiovascular disease relative to those without the disease, leading to a markedly diminished life span ( $\mathrm{Gu}$ et al., 1998; Resnick and Howard, 2002; Taylor et al., 2013). Macrovascular complications of diabetes, 
including coronary artery disease, stroke, peripheral artery disease, and microvascular disturbances, such as retinopathy, nephropathy, and neuropathy, along with limb amputations, are responsible for much of the burden associated with this metabolic disease (Beckman et al., 2002; Fowler, 2008). Aside from its profound effect on the duration and quality of life, the increasing worldwide prevalence of diabetes will impose a severe and costly demand on health services, further emphasizing the need to develop novel therapies to manage the cardiovascular complications arising from the disease.

The pathogenesis of vascular disease in diabetes is complex and multifactorial; however, abnormalities in endothelial function play a predominant role (Creager et al., 2003; Xu and Zou, 2009). The endothelium forms the inner layer of blood vessels and is a key regulator of vascular structure and function. Besides their barrier function, endothelial cells (ECs) serve as an active signal transducer that modulates vessel wall phenotype. ECs dynamically control vascular permeability, tone, thrombosis, inflammation, and vascular smooth muscle cell proliferation and migration by synthesizing a plethora of mediators (Vane et al., 1990). Endothelial dysfunction, as represented by attenuated endothelium-dependent vasorelaxation, is a salient feature of diabetes. It has been extensively documented in animal models of diabetes and in human blood vessels from diabetic patients (Meraji et al., 1987; Durante et al., 1988; Williams et al., 1996; De Vriese et al., 2000; Rask-Madsen and King, 2007). In addition, impaired EC proliferation and migration are often detected in diabetes, and this underlies the blunted angiogenic response observed in most tissues (Santilli et al., 1992; Yan et al., 2009; Warren et al., 2014). Many of the metabolic derangements known to occur in diabetes adversely affect EC function, but hyperglycemia is believed to play a predominant role (Brownlee, 2005).

Sodium-glucose co-transporter 2 (SGLT2) inhibitors are the latest approved class of glucose-lowering drugs (Kalra, 2014). By blocking glucose uptake in the proximal tubule of the nephron, they induce glycosuria leading to decreases in both fasting and postprandial glycemia. Intriguingly, large, multicenter, clinical trials such as the EMPA-REG-OUTCOME, the CANVAS Program, and the CV-REAL Nordic have demonstrated that SGLT2 inhibitors (empagliflozin, canagliflozin, and dapagliflozin) reduce cardiovascular disease and mortality compared to other anti-hyperglycemic agents in patients with type 2 diabetes mellitus (T2DM) (Zinman et al., 2015; Birkeland et al., 2017; Neal et al., 2017). In fact, canagliflozin was recently approved by the United States Food and Drug administration for the prevention of myocardial infarction, stroke, and death among patients with type 2 diabetes, who have established cardiovascular disease. However, canagliflozin treatment was associated with a significant risk of lower limb amputations in T2DM patients, which is not seen with other SGLT2 inhibitors (Zinman et al., 2015; Birkeland et al., 2017; Fadini and Avigari, 2017; Neal et al., 2017).

The mechanisms underlying the cardiovascular benefits or amputation risk of the SGLT2 inhibitors remains unknown but they do not appear to be mediated by differential improvements in glycemic control (Zinman et al., 2015; Birkeland et al., 2017; Neal et al., 2017). While reductions in blood pressure, arterial stiffness, body weight, visceral adiposity, and/or intrarenal hemodynamics have been suggested to contribute to the cardiovascular benefits of the SGLT2 inhibitors, direct effects of these drugs on vascular cell function have not been fully considered. Given the important role that EC dysfunction plays in promoting diabetes-associated vascular disease and limb ischemia and the discrepant impact of canagliflozin on limb amputation, the present study tested the hypothesis that canagliflozin, but not other SGLT2 inhibitors, impairs EC function and angiogenesis.

\section{MATERIALS AND METHODS}

\section{Materials}

M199 medium, streptomycin, penicillin, gelatin, heparin, trypsin, ethylenediaminetetraacetic acid (EDTA), sodium dodecyl sulfate (SDS), $\mathrm{NaOH}$, elastase, cesium chloride, collagenase, phosphatebuffered saline (PBS), RNase, propidium iodide, glycerol, bromophenol blue, isolectin B4, and mercaptoethanol were from Sigma-Aldrich (St. Louis, MO). Matrigel and endothelial cell growth factor were from BD Biosciences (San Jose, CA). Antibodies against cyclin D1, cyclin E, cyclin A, p21, p27, platelet endothelial cell adhesion molecule-1 (PECAM-1), SGLT2, and $\beta$-actin were from Santa Cruz Biotechnology (Santa Cruz, CA), the antibody against SGLT1 was from GeneTex (Irvine, CA), and the antibody against phospho-retinoblastoma protein was from Cell Signaling Technologies (Beverley, MA). $\left[{ }^{3} \mathrm{H}\right]$ Thymidine $(20 \mathrm{Ci} / \mathrm{mmol})$ was from Perkin Elmer (Boston, MA). Canagliflozin, empagliflozin, and dapagliflozin were purchased from Selleck Chemicals (Houston, TX).

\section{Animals}

Male C57BL/6 mice (9-10 weeks of age) were obtained from the Jackson Laboratory (Bar Harbor, ME) and housed in animal care facilities of the University of Missouri. They were maintained at $\sim 24^{\circ} \mathrm{C}$ on a $12-12 \mathrm{~h}$ light-dark cycle with food and water available ad libitum for at least a week before use. For the EC isolation experiments, mice were anesthetized by an intraperitoneal injection of ketamine $(87.5 \mathrm{mg} / \mathrm{kg}) /$ xylazine (12.5 mg/kg) cocktail (Butler Schein Animal Health Corporation, Dublin, $\mathrm{OH}$ ), and aortas harvested for EC isolation and culture, as described below. For the capillary sprouting experiments, mice were anesthetized with isoflurane $\left(2-4 \%\right.$ in $\left.100 \% \mathrm{O}_{2}\right)$ and aortas collected for the ex vivo experiments. This study was approved by the institutional Animal Care-Use Committees of the University of Missouri and the Truman VA Hospital (Columbia, MO, USA) and performed in accordance with the National Research Council's Guide for the Care and Use of Laboratory Animals.

\section{Cell Culture}

Primary human umbilical vein ECs (HUVECs) and human aortic ECs (HAECs) were purchased from Lonza Incorporated (Allendale, NJ), while primary mouse aortic ECs (MAECs) were isolated by plating mouse thoracic aortas on matrigel-coated plates and purifying MAEC outgrowth with a PECAM-1 antibody, 
as we have previously described (Liu et al., 2013). Primary cells were characterized as ECs by both positive staining for PECAM-1 and uptake of acetylated low-density lipoprotein by $95 \%$ of cells. Cells were serially cultured on gelatin-coated plates in M199 medium supplemented with $20 \%$ bovine calf serum, $2 \mathrm{mM}$ L-glutamine, $50 \mu \mathrm{g} / \mathrm{ml}$ EC growth factor, $90 \mu \mathrm{g} / \mathrm{ml}$ heparin, and $100 \mathrm{U} / \mathrm{ml}$ of penicillin and streptomycin. All cells were incubated at $37^{\circ} \mathrm{C}$ in an atmosphere of $95 \%$ air and $5 \% \mathrm{CO}_{2}$.

\section{Cell Proliferation and DNA Synthesis}

ECs were seeded $\left(2 \times 10^{4}\right.$ cells/well $)$ onto six-well plates in serum-containing media. After $24 \mathrm{~h}$, cells were washed and treated with vehicle or SGLT2 inhibitors. Media with appropriate additions were replenished every second day. Cell number determinations were performed at various times by dissociating cells with trypsin (0.05\%):EDTA $(0.53 \mathrm{mM})$ and counting cells using an automated cell counter (Moxi Z ORFLO Technologies, Ketchum, ID). EC proliferation was also monitored by measuring DNA synthesis (Peyton et al., 2012). Briefly, cells were pulsed with $\left[{ }^{3} \mathrm{H}\right]$ thymidine $(1 \mu \mathrm{Ci} / \mathrm{ml}[0.037 \mathrm{MBq}])$ for $4 \mathrm{~h}$, washed with ice-cold PBS, fixed with $10 \%$ trichloroacetic acid for $30 \mathrm{~min}$ at $4^{\circ} \mathrm{C}$, and DNA extracted with $0.2 \%$ SDS $/ 0.2 \mathrm{~N} \mathrm{NaOH}$. Radioactivity was determined by scintillation counting (Tricarb liquid scintillation analyzer, model 2100, Packard, Meriden, CT).

\section{Cell Cycle Analysis}

Cell cycle distribution was assessed in ECs grown to 70-80\% confluence by flow-activated cell sorting (Peyton et al., 2012). Cells were treated in the presence and absence of SGLT2 inhibitors for $24 \mathrm{~h}$. Cells were then collected, suspended in PBS, and pelleted by centrifugation at $1,000 \mathrm{~g}$ for $5 \mathrm{~min}$. Pellets were washed with PBS, suspended in $70 \%$ ethanol, and fixed overnight at $4^{\circ} \mathrm{C}$. Fixed cells were then incubated with propidium iodide $(50 \mu \mathrm{g} / \mathrm{ml})$ and RNase A $(100 \mu \mathrm{g} / \mathrm{ml})$ for $60 \mathrm{~min}$ at room temperature, and DNA fluorescence measured in a Beckman Coulter CyAN ADP Cytometer (Brea, CA). Flow cytometry results were analyzed using FlowJo ${ }^{\mathrm{TM}}$ software (FlowJo LLC, Ashland, OR, USA).

\section{Cell Migration}

EC migration was determined using the scratch-wound assay (Chang et al., 2014). Confluent cell monolayers were scraped with a pipette tip to generate a wound. Cell debris was removed by several washes with PBS, and injured monolayers incubated in the presence or absence of SGLT2 inhibitors. Cell monolayers were photographed immediately and $20 \mathrm{~h}$ after scratch injury with a digital camera (Q-Imaging, QICAM; Hitschfel Instruments, Incorporated, St. Louis, MO), and the degree of wound closure determined by planimetry.

\section{Endothelial Cell Tube Formation}

ECs $\left(2 \times 10^{5}\right.$ cells/well $)$ were seeded in 48 -well plates that had been pre-coated with matrigel $(50 \mu \mathrm{l} /$ well). After incubation for $6 \mathrm{~h}$ in serum-containing media, images of tube morphology were captured by an inverted Olympus CKX41 microscope (Olympus America, Inc., Center Valley, PA), and the extent of tube formation quantified by counting the number of meshes (Khoo et al., 2011).

\section{Aortic Ring Capillary Sprouting Assay}

Aortas were cut into $1 \mathrm{~mm}$ segments and then embedded and cultured in fibrinogen gels $(3 \mathrm{mg} / \mathrm{ml}$ fibrinogen in Opti-MEM including $1 \mu \mathrm{l} / \mathrm{ml}$ thrombin) in 48 well plates, as previously described (Kiefer et al., 2004; West and Burbridge, 2009). Aortic segments were cultured in Opti-MEM (Thermofisher, Grand Island, NY) supplemented with either vascular endothelial growth factor (VEGF)- $\mathrm{A}_{164}(10 \mathrm{ng} / \mathrm{ml}$, Invitrogen Corporation, Carlsbad, CA) alone or plus canagliflozin $(10,20$, or $50 \mu \mathrm{M})$ for 5 days, changing the media every 2-3 days. Canagliflozin was prepared in DMSO, and accordingly, VEGF- $\mathrm{A}_{164}$ alone treated aortas also received $0.1 \%$ DMSO as a vehicle control. Three aortic segments from each animal received each treatment. At 5 days, segments were fixed with 3\% paraformaldehyde and stained with FITC-conjugated isolectin $\mathrm{B}_{4}$ (Sigma-Aldrich, St. Louis, MO). Two Z-stack images of sprouting were collected from each segment via fluorescence confocal microscopy (Leica TCS SPE, Buffalo Grove, IL) and EC sprouting networks were reconstructed in 3D (Imaris; Bitplane AG, Zurich) to quantify total volume of sprouting networks.

\section{Lactate Dehydrogenase Activity Assay}

Lactate dehydrogenase activity was measured using the CytoTox 96 Non-Radioactive Cytotoxicity Assay (Promega Life Sciences). Briefly, cells were seeded in 24 -well plates and treated with SGLT2 inhibitors for $24 \mathrm{~h}$ at $37^{\circ} \mathrm{C}$. After centrifugation, an aliquot of the supernatant was transferred to a 96-well plate, followed by addition of an equal amount of CytoTox 96 reagent. After $30 \mathrm{~min}$ of incubation at room temperature, acetic acid (1 M) was added to stop the reaction and absorbance at $490 \mathrm{~nm}$ measured by spectroscopy ( $\mu$ Quant spectrophotometer, Bio-Tek Instruments, Winooski, VT). Lactate dehydrogenase activity was reported as a percentage of control cells.

\section{Western Blotting}

ECs were harvested in electrophoresis buffer (125 mM Tris, pH 6.8, 12.5\% glycerol, 2\% SDS, and trace bromophenol blue), and proteins separated by SDS-polyacrylamide gel electrophoresis. After electrophoretic transfer to nitrocellulose membranes, membranes were blocked with PBS and nonfat milk (5\%), and then incubated overnight at $4{ }^{\circ} \mathrm{C}$ with primary antibodies against cyclin D1 (1:200), cyclin E (1:100), cyclin A (1:500), p27 (1:250), p21 (1:250), SGLT1 (1:1,500), SGLT2 (1:100), phospho-retinoblastoma protein (1:100), or $\beta$-actin $(1: 200)$. Membranes were then washed extensively in PBS and incubated with appropriate horseradish peroxidase-labeled secondary antibodies for $60 \mathrm{~min}$ at room temperature. Afterward, membranes were incubated with enhanced chemoluminescence substrate for horse radish peroxidase (GE Healthcare, Chicago, IL) and the signal intensity detected by X-ray film exposure. Blots were then stripped of antibodies by incubating membranes at $50^{\circ} \mathrm{C}$ for 30 min with a stripping buffer $(10 \%$ SDS and $100 \mathrm{mM}$ mercaptoethanol, in $62.5 \mathrm{mM}$ Tris buffer, 
$\mathrm{pH}$ 6.8) before probing with other primary antibodies. Protein expression was determined by densitometry and normalized with respect to $\beta$-actin (Peyton et al., 2012).

\section{Cyclin A Adenovirus Infection}

An adenovirus expressing cyclin A (AdCyclin A) was created by cloning the human cyclin A cDNA in the pAACMVpLpA vector and co-transfecting HEK-293 cells (American Type Culture Collection, Manassas, VA) with the pJM17 plasmid (Wang et al., 2002). Virus from cytopathic HEK-293 cells was collected $48 \mathrm{~h}$ post infection, purified by gradient cesium chloride centrifugation, and viral titers measured by plaque assay. Subconfluent HUVECs were infected with AdCyclin A or a control adenovirus expressing the green fluorescent protein (AdGFP) at a multiplicity of infection of 50 for $24 \mathrm{~h}$ prior to treatment with the SGLT2 inhibitors.

\section{Statistical Analysis}

Results are expressed as mean \pm SEM of at least three independent experiments. Statistical analyses were performed with the use of a Student's two tailed $t$-test and one way analysis of variance with the Holm-Sidak post-hoc test when more than two treatment regimens were compared. $p$ less than 0.05 were considered statistically significant.

\section{RESULTS}

Treatment of HUVECs with canagliflozin resulted in a concentration-dependent inhibition of DNA synthesis
(Figure 1A). The ability of canagliflozin to block DNA synthesis was observed at concentrations $(5-10 \mu \mathrm{M})$ (Figure 1A) that are achieved in the plasma of patients taking canagliflozin (Devineni et al., 2015). Moreover, DNA synthesis was nearly abolished with a higher concentration of canagliflozin $(50 \mu \mathrm{M})$. In contrast, clinically relevant concentrations of empagliflozin and dapagliflozin (1-2 $\mu \mathrm{M}$ ) (Kasichayanula et al., 2011; Brand et al., 2012) failed to inhibit DNA synthesis (Figures 1B,C). However, at very high concentrations $(30-50 \mu \mathrm{M})$, empagliflozin and dapagliflozin modestly attenuated DNA synthesis. Notably, the inhibition of DNA synthesis by these three SGLT2 inhibitors was not related to any change in cell viability, as assessed by lactate dehydrogenase activity measurements (Figures 1D-F). In addition, incubation of HUVECs with canagliflozin induced a concentration-dependent decrease in cell proliferation, as assessed by direct cell counting (Figure 2A). A significant inhibition of cell growth by canagliflozin was noted beginning at the pharmacologically relevant concentration of $5 \mu \mathrm{M}$. The anti-proliferative effect of canagliflozin was detected 1 day after treatment, and this was further magnified after 3 days of canagliflozin exposure (Figure 2B). In contrast, only high concentrations $(30-50 \mu \mathrm{M})$ of empagliflozin and dapagliflozin inhibited the proliferation of HUVEC (Figures 2C,D). Furthermore, pharmacologically relevant concentrations of canagliflozin also inhibited the proliferation of HAECs and MAECs (Figures 3A,B).

Subsequently, we determined the effect of canagliflozin on cell cycle progression. Administration of canagliflozin-arrested HUVECs in the $G_{0} / G_{1}$ phase of the cell cycle, as demonstrated by an increase in the percentage of cells in $G_{0} / G_{1}$ with a
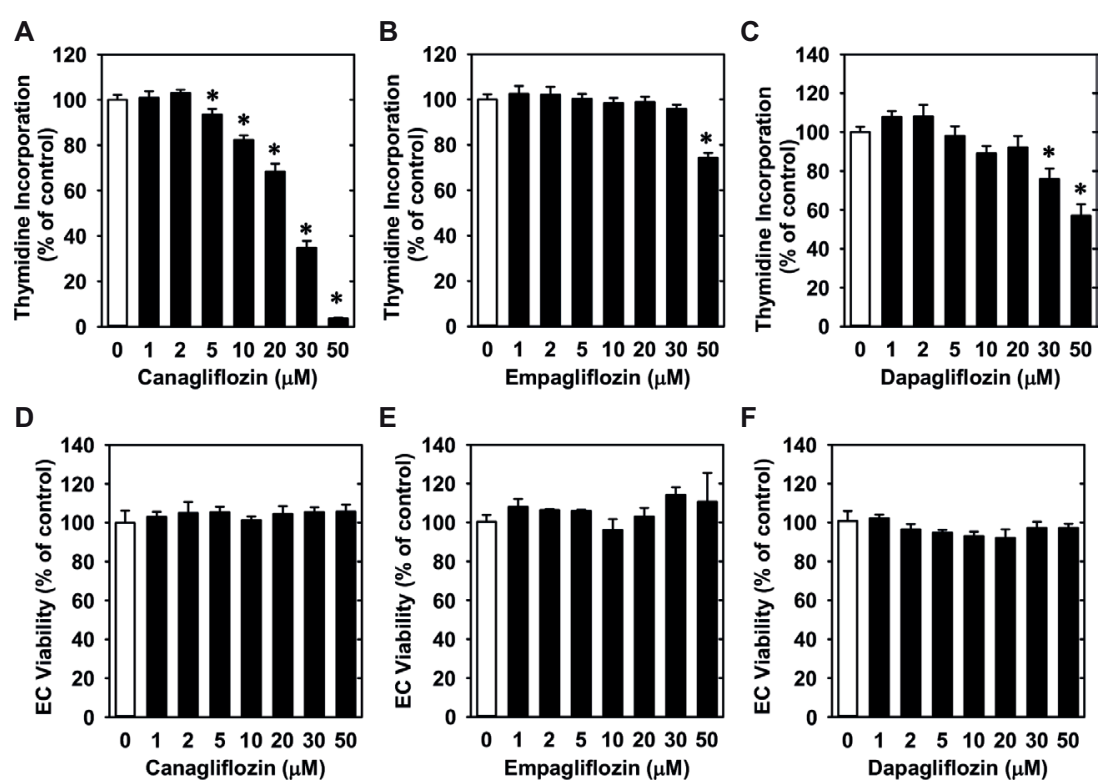

FIGURE 1 | Effect of SGLT2 inhibitors on DNA synthesis and viability of HUVECs. (A-C) Effect of canagliflozin, empagliflozin, and dapagliflozin on DNA synthesis in HUVECs. Cells were treated with SGLT2 inhibitors $(0-50 \mu \mathrm{M})$ for $24 \mathrm{~h}$. Results are mean \pm SEM $(n=6-8)$. (D-F) Canagliflozin, empagliflozin, and dapagliflozin do not stimulate lactate dehydrogenase activity in the culture media of HUVECs. Cells were treated with SGLT2 inhibitors (0-50 $\mu \mathrm{M})$ for 24 h. Results are mean \pm SEM $(n=4)$. ${ }^{*}$ Statistically significant effect of SGLT2 inhibitors. 

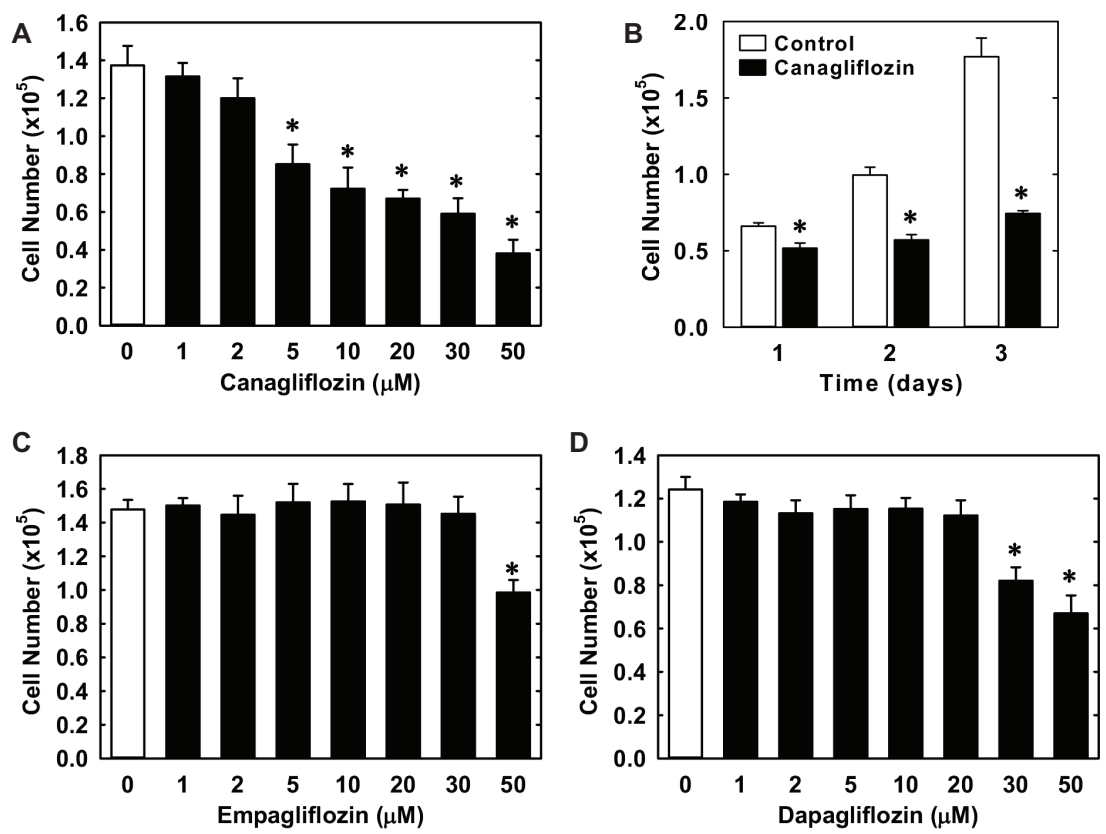

FIGURE 2 | Effect of SGLT2 inhibitors on the proliferation of HUVECs. (A) Canagliflozin inhibits the proliferation of HUVECs in a concentration-dependent manner. Cells were treated with canagliflozin (0-50 $\mathrm{MM}$ ) for 3 days. (B) Canagliflozin inhibits the proliferation of HUVECs after 1, 2, and 3 days of drug exposure. Cells were treated with canagliflozin $(50 \mu \mathrm{M})$ for up to 3 days. (C) Empagliflozin inhibits the proliferation of HUVECs in a concentration-dependent manner. Cells were treated with empagliflozin (0-50 $\mu \mathrm{M})$ for 3 days. (D) Dapagliflozin inhibits the proliferation of HUVECs in a concentration-dependent manner. Cells were treated with dapagliflozin $(0-50 \mu \mathrm{M})$ for 3 days. Results are mean \pm SEM $(n=6)$. *Statistically significant effect of SGLT2 inhibitors.

corresponding decline in the fraction of cells in $S$ and $G_{2} / M$ phases (Figures 4A,B). To determine the mechanism by which canagliflozin disrupts cell cycle progression, we examined the effect of canagliflozin on the expression of cell cycle regulatory proteins. Canagliflozin dramatically reduced the expression of cyclin $\mathrm{A}$ and the phosphorylation of retinoblastoma protein (Figures 4C,D). In contrast, canagliflozin had no significant effect on the expression of cyclin D1 and E and the cyclindependent kinase inhibitors p27 and p21. Western blotting also revealed the presence of both SGLT1 and SGLT2 in HUVECs (Figure 4E). Given the strong inhibition of cyclin A by canagliflozin, we tested whether restoration of cyclin A levels would negate the anti-proliferative effect of the SGLT2 inhibitor. Infection of HUVECs with AdCyclin A restored cyclin A protein expression in the presence of canagliflozin and partially rescued EC proliferation in the canagliflozintreated cells (Figures 5A,B).

Lastly, we investigated the effect of canagliflozin on EC migration and differentiation. While high concentrations of canagliflozin and empagliflozin $(50 \mu \mathrm{M})$ had a modest inhibitory effect on the migration of HUVECs, dapagliflozin had no effect on EC motility (Figures 6A-C). However, canagliflozin strongly inhibited tube formation by HUVECs starting at a concentration of $20 \mu \mathrm{M}$ (Figure 7A), whereas empagliflozin and dapagliflozin did not affect endothelial tube formation (Figures 7B,C). Finally, canagliflozin also blocked the sprouting of EC capillaries from mouse aortic rings cultured in a fibrinogen gel. Five days after culture, extensive EC capillary sprouting was observed in untreated aortas, and this was markedly attenuated by canagliflozin in a concentration-dependent fashion (Figure 7D). A downward trend in EC sprouting was noted at a concentration of $20 \mu \mathrm{M}(p=0.098)$ and a significant decrease in sprouting was observed at $50 \mu \mathrm{M}$ (Figure 7E).

\section{DISCUSSION}

The present study demonstrates that canagliflozin is a robust inhibitor of EC proliferation. The anti-proliferative action of canagliflozin is observed in human ECs derived from both the venous and arterial circulation as well as ECs isolated from the murine circulation and is dependent, in part, on the suppression of cyclin A expression. This study also found that canagliflozin blocks endothelial tube formation from cultured ECs and isolated mouse aortic rings. In contrast, empagliflozin and dapagliflozin minimally affects EC proliferation and tube formation. The ability of canagliflozin to elicit these pleiotropic actions on EC function may contribute to the increased risk of limb amputation noted in diabetic patients taking this drug by impairing angiogenesis (Neal et al., 2017).

This study is the first to show that canagliflozin is an inhibitor of EC proliferation and DNA synthesis. The antiproliferative action of canagliflozin is concentration-dependent, and significantly, is observed at concentrations $(10 \mu \mathrm{M})$ that 

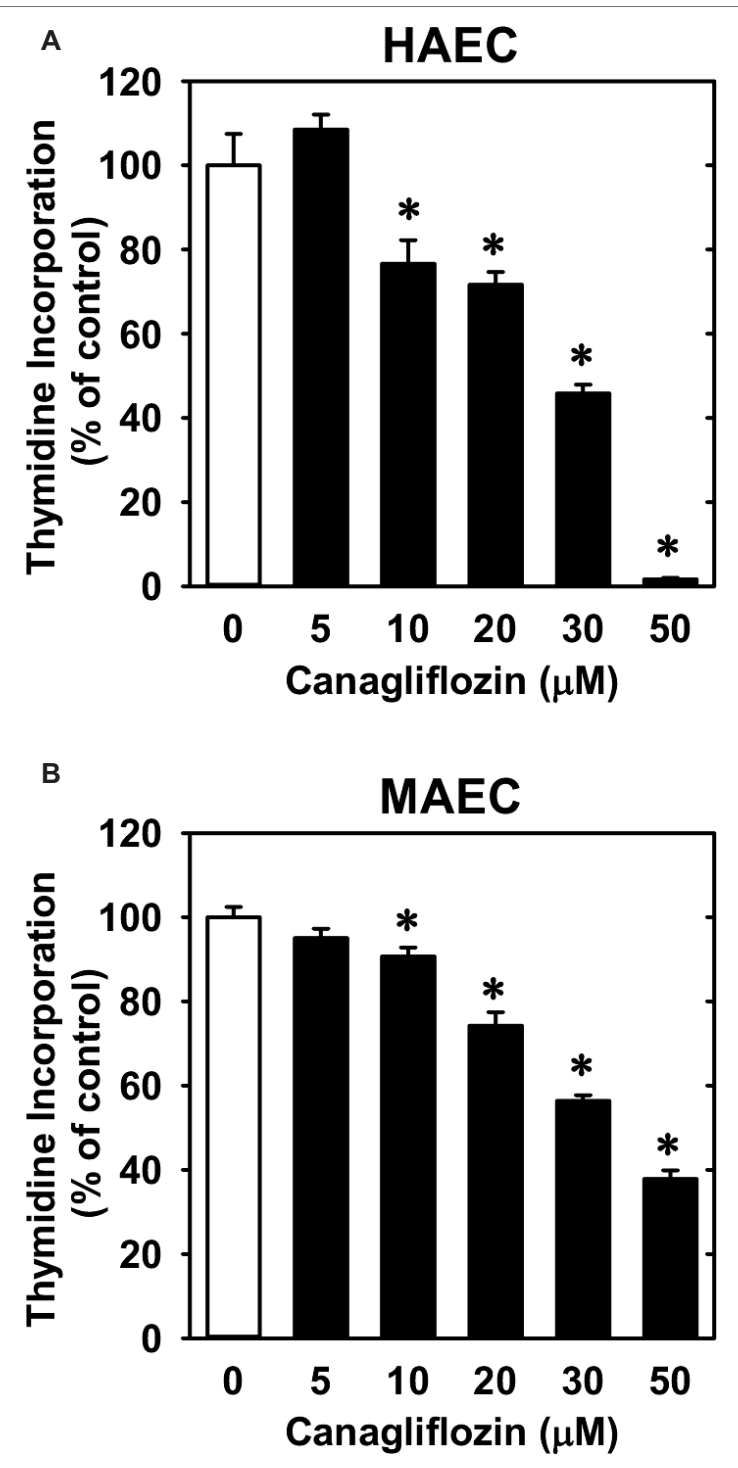

FIGURE 3 | Effect of canagliflozin on DNA synthesis in HAECs and MAECs. (A,B) HAECs or MAECs were treated with canagliflozin (0-50 $\mu \mathrm{M})$ for $24 \mathrm{~h}$. Results are mean \pm SEM $(n=6)$. *Statistically significant effect of canagliflozin.

are achieved in the plasma of patients treated with this particular SGLT2 inhibitor (Devineni et al., 2015). The blockade of EC proliferation by canagliflozin occurs in the absence of cell death as revealed by lactate dehydrogenase activity measurements and the lack of a sub $G_{0} / G_{1}$ fraction in the cell cycle histograms, indicating that canagliflozin functions in a cytostatic rather than cytotoxic manner. The anti-proliferative action of canagliflozin appears uniform as it was observed in ECs derived from the human arterial and venous circulation as well as the mouse arterial circulation. Interestingly, the degree of inhibition is greater in human relative to mouse ECs, suggesting that human cells may be more sensitive to the growth-inhibitory action of canagliflozin. Moreover, the inhibition of EC growth by canagliflozin likely represents a compound-specific effect rather than a class effect since pharmacologically relevant concentrations of other SGLT2 inhibitors including empagliflozin and dapagliflozin (1-2 $\mu \mathrm{M})$ (Kasichayanula et al., 2011; Brand et al., 2012) failed to block EC proliferation. Thus, this study adds to a growing list of off-targets actions elicited by canagliflozin, and further underscores the need to consider these pleiotropic effects when assessing the clinical properties of the drug (Pattanawongsa et al., 2015; Hawley et al., 2016; Villani et al., 2016; Mancini et al., 2018; Secker et al., 2018; Uthman et al., 2018).

Our finding that canagliflozin blocks EC proliferation is in agreement with earlier studies documenting robust inhibitor effects of canagliflozin on the replication of renal proximal tubule epithelial cells, lung, liver, and prostate cancer cells, and on the in vivo growth of xenograft tumors in athymic nude mice (Villani et al., 2016; Kaji et al., 2018; Secker et al., 2018). Notably, our results are in contrast to recent reports showing that canagliflozin has no effect on the proliferation of HUVECs (Kaji et al., 2018; Mancini et al., 2018). However, these studies examined only a single concentration of the drug over a short time period (24 and $36 \mathrm{~h}$ ), which may be a suboptimal time interval to detect differences in the rate of cell growth. Consistent with this notion, we found that the anti-proliferative effect of canagliflozin was much greater at $72 \mathrm{~h}$ than after $24 \mathrm{~h}$ of drug exposure. Thus, longer duration experiments more closely resembling long-term use in human patients are better able to identify the anti-proliferative potential of canagliflozin in ECs.

EC proliferation involves the progression of cells through discrete stages of the cell cycle, where DNA synthesis and mitosis occur. Examination of the cell cycle distribution revealed that canagliflozin arrests ECs in the $G_{0} / G_{1}$ phase of the cell cycle and is associated with a prominent decrease in the phosphorylation of retinoblastoma protein and reduced expression of cyclin $\mathrm{A}$, without altered expression of other cyclins or cyclin-dependent kinase inhibitors. The hypophosphorylation of retinoblastoma protein detected after canagliflozin treatment keeps the protein in its growthrepressive state, which curbs the transcription of genes, including cyclin $\mathrm{A}$, that are required for DNA synthesis (Weinberg, 1995). Moreover, cyclin A promotes the phosphorylation and deactivation of retinoblastoma protein via its interaction with cyclin-dependent kinase 2, highlighting crucial interactions between these two proteins that direct cell cycle progression. Of significance, we demonstrate that adenoviral-mediated rescue of cyclin A expression in canagliflozin-treated ECs increases DNA synthesis in these cells, establishing that cyclin $\mathrm{A}$ is a critical target of canagliflozin. The mechanism by which canagliflozin inhibits cyclin A expression is not known. However, recent work from our laboratory and others have shown that the metabolism and entry of glutamine into the tricarboxylic acid cycle plays a fundamental role in stimulating cyclin A expression and EC proliferation (Huang et al., 2017; Kim et al., 2017; Peyton et al., 2018). Intriguingly, a recent report found that clinically relevant concentrations of canagliflozin, but not empagliflozin 

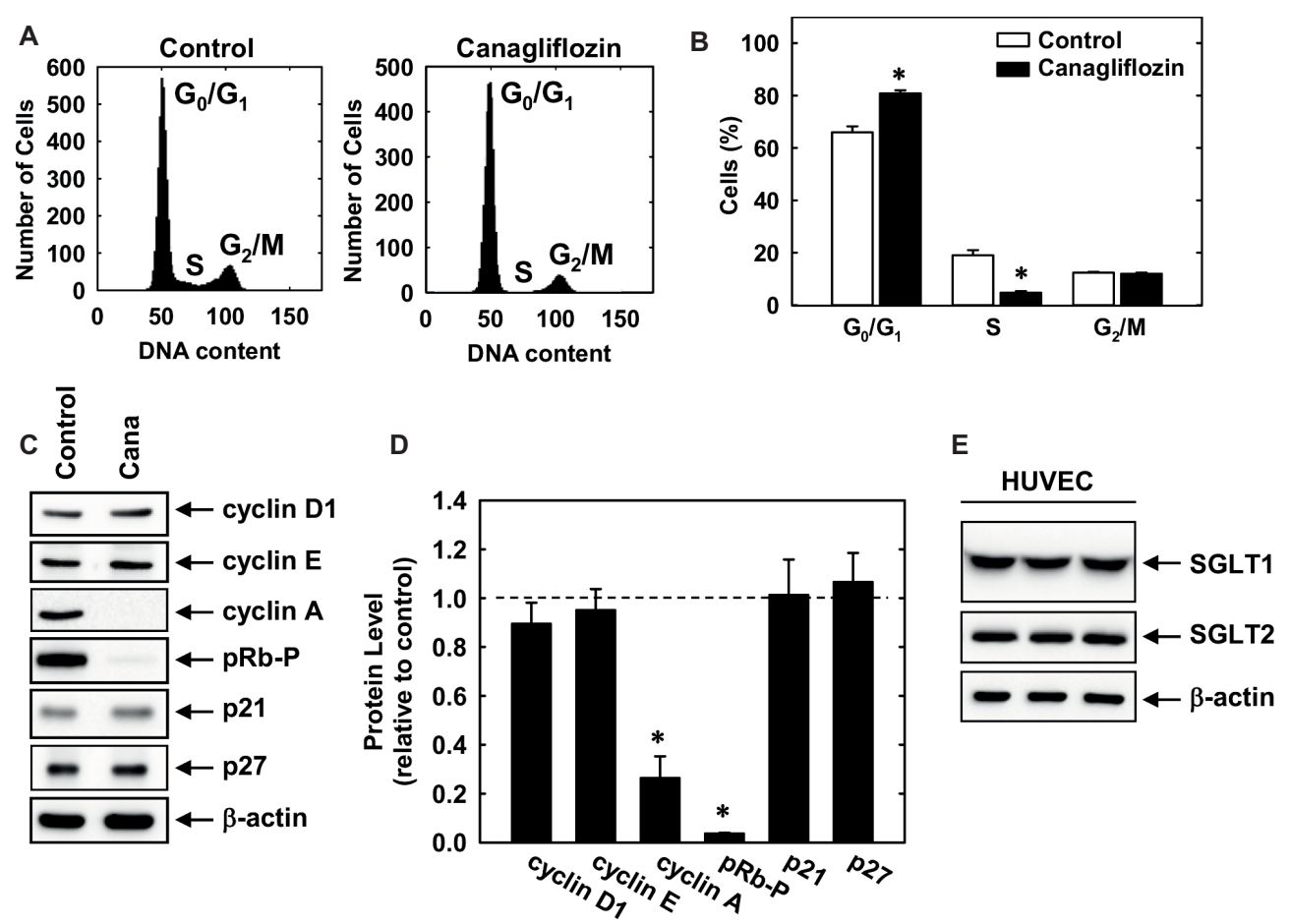

FIGURE 4 | Cell cycle progression and protein expression and phosphorylation in HUVECs. (A) Representative histograms of HUVECs treated for $24 \mathrm{~h}$ in the absence or presence of canagliflozin $(50 \mu \mathrm{M})$. (B) Effect of canagliflozin $(50 \mu \mathrm{M})$ on the distribution of HUVECs in the cell cycle. (C) Effect of canagliflozin on the expression and phosphorylation of cell cycle regulatory proteins in HUVECs. Cells were incubated in the absence and presence of canagliflozin (50 $\mu \mathrm{M})$ for $24 \mathrm{~h}$, and protein expression and phosphorylation determined by western blotting. (D) Quantification of protein expression or phosphorylation relative to control cells. (E) HUVECs express SGLT1 and SGLT2 protein. Cell lysates from HUVEC (three independent lanes) were resolved by SDS-polyacrylamide gel electrophoresis and immunoblotted with anti-SGLT antibodies. Results are means \pm SEM $(n=6)$. *Statistically significant effect of canagliflozin.

or dapagliflozin, prevent the replenishment of tricarboxylic acid cycle intermediates by glutamine via the dual inhibition of mitochondrial glutamate dehydrogenase and complex I (Secker et al., 2018), raising the possibility that canagliflozin may also retard cyclin A expression and the propagation of ECs by suppressing mitochondrial metabolism.

Notably, restoration of cyclin A does not fully restore DNA synthesis, suggesting that other factors may also contribute to the anti-proliferative action of canagliflozin. Consistent with an earlier study (Mancini et al., 2018), we found that HUVEC express SGLT2 protein. Aside from ECs, SGLT2 is found in multiple cancer cells, where it stimulates tumor growth (Kaji et al., 2018; Scafoglio et al., 2018). However, it is unlikely that inhibition of this transporter by canagliflozin mediates its anti-proliferative action in ECs as similar effects would have been observed with pharmacologically relevant concentrations of empagliflozin and dapagliflozin. Interestingly, we show for the first time that HUVECs also express SGLT1, extending previous work reporting the presence of SGLT1 in microvascular endothelial cells of the brain and heart (Elfeber et al., 2004; Sajja et al., 2014; Vrhovac et al., 2015). While canagliflozin has a relatively weak selectivity for SGLT2 over SGLT1 compared to empagliflozin and dapagliflozin (Liang et al., 2012; Kurosaki and Ogasawara, 2013), it is doubtful that canagliflozin evokes its anti-proliferative effect through SGLT1 since this glucose transporter is associated with cell survival rather than proliferation (Weihua et al., 2008). Alternatively, our laboratory has previously identified AMP-activated protein kinase (AMPK) as a potent inhibitor of EC growth (Peyton et al., 2012). Interestingly, a recent report found that clinically relevant concentrations of canagliflozin, but not empagliflozin or dapagliflozin, activate this kinase (Hawley et al., 2016), raising the possibility that AMPK may also participate in the selective growth inhibitory action of canagliflozin.

We also found that canagliflozin blocks the migration of ECs. However, a moderate decrease in EC motility was only observed at a high concentration of canagliflozin $(50 \mu \mathrm{M})$, and this was also seen with elevated concentrations of empagliflozin but not dapagliflozin. Importantly, however, canagliflozin markedly attenuated the differentiation of ECs into tubes. This effect by canagliflozin was observed with a concentration of $20 \mu \mathrm{M}$ and is unique to this drug as it was not detected with either empagliflozin or dapagliflozin. Furthermore, the ability of canagliflozin to block endothelial tube formation was confirmed using an in situ sprouting assay in mouse aortic rings. Canagliflozin tended to reduce sprouting at a concentration of $20 \mu \mathrm{M}$ and significantly inhibited sprouting 


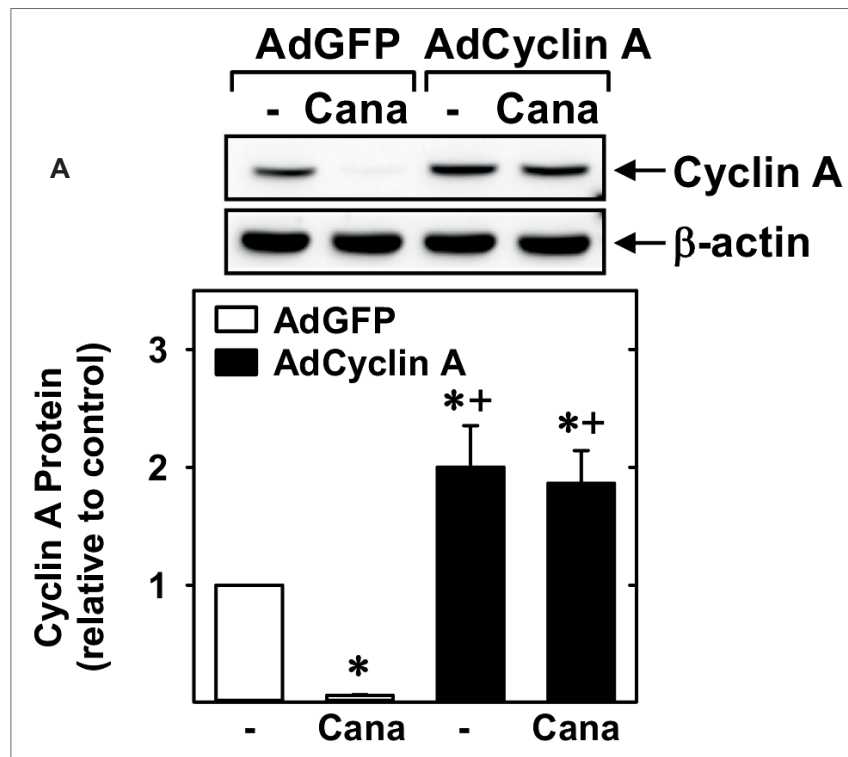

B

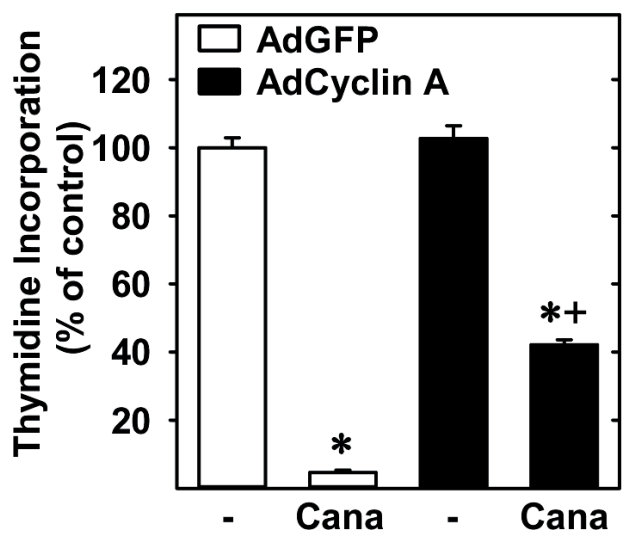

FIGURE 5 | Role of cyclin A in the anti-proliferative action of canagliflozin. (A) AdCyclin A increases cyclin A protein levels in canagliflozin (Cana)-treated HUVECs. Results are mean \pm SEM $(n=3)$. (B) AdCyclin A increased DNA synthesis in Cana-treated HUVECs. Cells were infected with AdCyclin A or AdGFP $(50 \mathrm{MOI})$ for $24 \mathrm{~h}$ and then incubated in the absence or presence of Cana $(50 \mu \mathrm{M})$ for another $24 \mathrm{~h}$ prior to measuring DNA synthesis. Results are mean $\pm \operatorname{SEM}(n=6)$. *Statistically significant effect of canagliflozin.

+Statistically significant effect of AdCyclin A.

at a concentration of $50 \mu \mathrm{M}$, consistent with the effect of canagliflozin on EC migration. These anti-angiogenic actions occur at concentrations exceeding the typical plasma concentration in the average T2DM patient but may be particularly relevant for individuals with preexisting chronic kidney disease, a history of kidney injury, or elderly patients subjected to polypharmacy that may be exposed to much higher concentrations of canagliflozin if appropriate dose adjustments are not made (Davies et al., 2016; Fusco et al., 2016). Further, as discussed above, our data suggest that human ECs may be more sensitive than murine ECs to canagliflozin, thus, we would speculate that sprouting by human ECs may be more robustly attenuated than our results indicate using the mouse aortic ring sprouting assay.

Our finding that canagliflozin robustly inhibits EC proliferation and tube formation is of potential pharmacological significance given that these processes contribute to vascular repair and angiogenesis. Indeed, a recent report demonstrates that canagliflozin reduces intra-tumor vascularization in a xenograft model of liver cancer (Kaji et al., 2018). Thus, aside from directly inhibiting tumor cell proliferation, canagliflozin may curb tumor growth by blocking the formation of new blood vessels that are needed to nourish the growing tumor. In a similar fashion, canagliflozin may be of benefit in patients with proliferative diabetic retinopathy, where unrestrained EC proliferation and angiogenesis contributes to the disease process (Simó et al., 2006). Moreover, since angiogenesis contributes to atherosclerotic plaque progression and vulnerability (Virmani et al., 2005; Camere et al., 2017), canagliflozin may also mitigate the increased burden of atherosclerosis and its clinical complications in diabetes. In support of this concept, canagliflozin has recently been demonstrated to attenuate the progression of atherosclerosis in atherogenic mice (NasiriAnsari et al., 2018). On a cautionary note, by impairing the proliferation and differentiation of ECs, canagliflozin may further minimize limb blood flow in T2DM patients suffering from peripheral arterial disease. Surprisingly, a recent report found that canagliflozin accelerates the recovery of hind limb blood flow following femoral artery ligation and excision in diabetic mice, suggesting that the increased risk of amputation reported with canagliflozin may not be related to an increase in limb ischemia (Sherman et al., 2018). However, this preclinical animal model does not fully mimic the clinical setting where chronic limb ischemia in T2DM patients arises from progressive and pervasive atherosclerosis. Finally, canagliflozin may negatively impact clinical outcomes following coronary angioplasty by impairing the re-endothelialization of injured arteries, which is dependent, in part, on the proliferation of ECs from the injured border zone or from branching vessels adjacent to the site of injury (Hagensen et al., 2012). Given these latter concerns, restricting canagliflozin use, or switching to other anti-hyperglycemic medications seems advisable in patients with peripheral artery disease or in patients undergoing coronary artery stenting.

Finally, our studies were done in cultured human ECs and isolated mouse arteries, which do not fully mimic the complex biochemical and biophysical interactions that occur in vivo. Although extension of our in vitro and ex vivo experiments to an intact animal is important, our finding that human ECs are more sensitive to the anti-proliferative action of canagliflozin than murine ECs, suggest that studies in rodents may not accurately reflect what occurs in humans. Another limitation in our study is that the mechanism by which canagliflozin blocks EC growth has not been fully disclosed. While inhibition of cyclin A expression contributes to the anti-proliferative effect of canagliflozin, other unidentified mediators are also involved. Moreover, our study detected the presence of both SGLT1 and SGLT2 in ECs. Given that a majority of active glucose uptake 

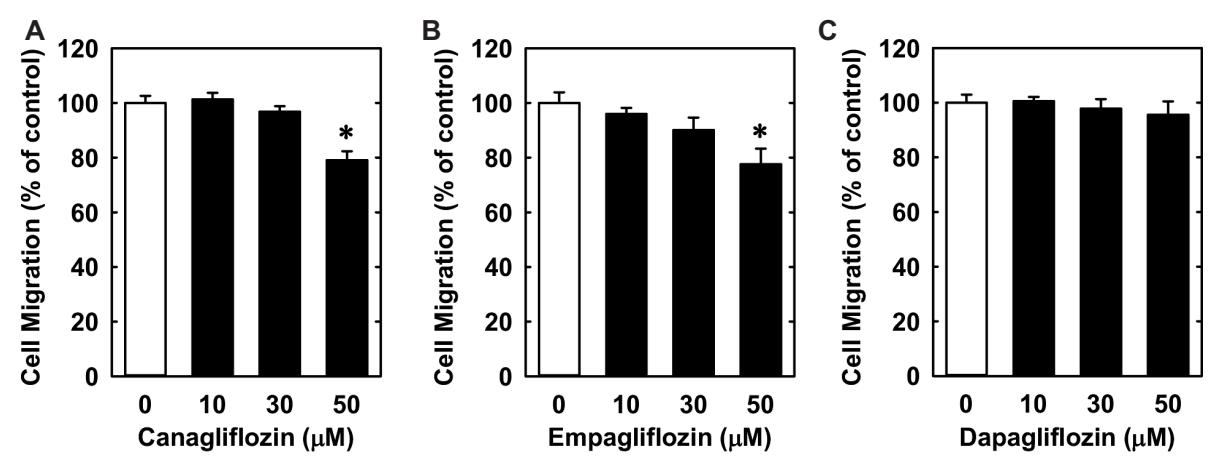

FIGURE 6 | Effect of SGLT2 inhibitors on the migration of HUVECs. (A-C) Effect of canagliflozin, empagliflozin, and dapagliflozin on the migration of HUVECs. Results are mean \pm SEM $(n=6)$. *Statistically significant effect of SGLT2 inhibitors.

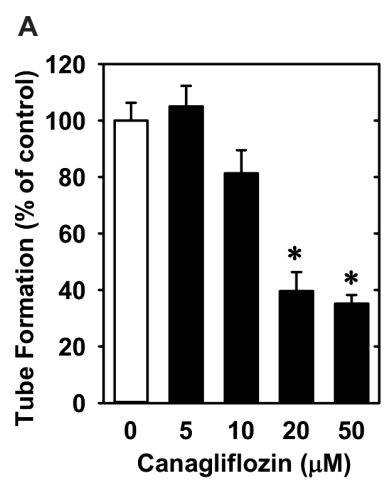

D

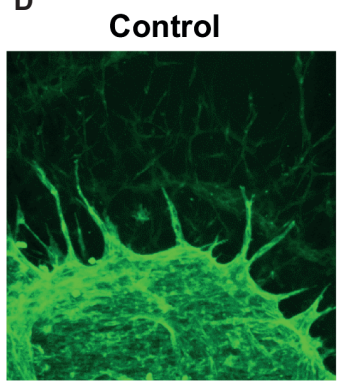

\section{B}

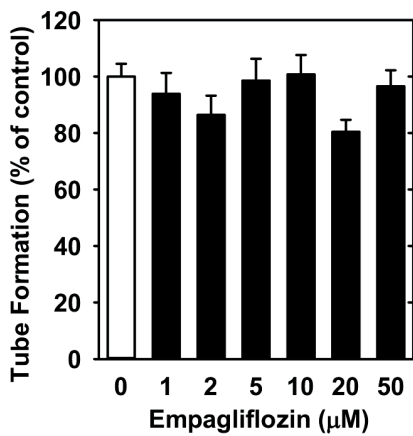

Canagliflozin $(50 \mu \mathrm{M})$

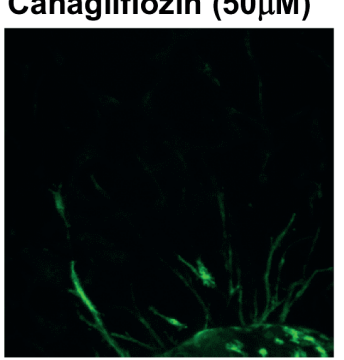

C

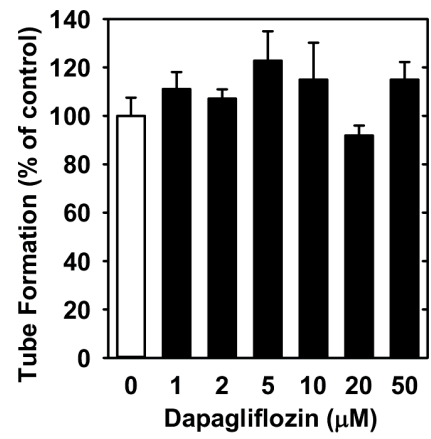

E

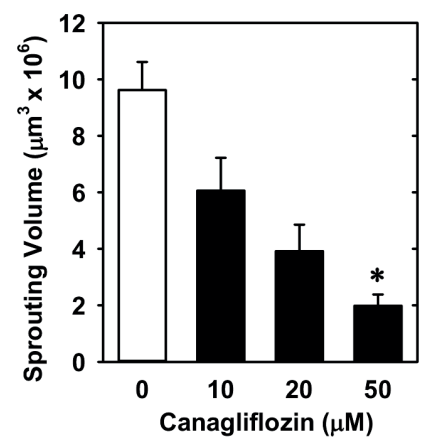

FIGURE 7 | Effect of SGLT2 inhibitors on EC tube formation. (A-C) Effect of canagliflozin, empagliflozin, and dapagliflozin on tube formation by HUVECs. (D) Representative two-dimensional images of EC capillary sprouting from control or canagliflozin-treated mouse aortic rings. Aortic rings were cultured for 5 days in fibrinogen gels in the absence or presence of canagliflozin $(50 \mu \mathrm{M})$ and $\mathrm{EC}$ capillary sprouting detected by fluorescence confocal microscopy following isolectin $\mathrm{B}_{4}$ staining. (E) Summary data showing the effect of canagliflozin on capillary sprouting from mouse aortic rings. Results are mean \pm SEM ( $n=4-8)$. ${ }^{*}$ tatistically significant effect of canagliflozin.

by ECs is mediated by the GLUT/SLC2A family of transporters (Tumova et al., 2016), the functional significance of SGLT1/2 in these cells is uncertain and will require additional studies.

In conclusion, the present study identified canagliflozin as a potent inhibitor of human EC proliferation. The antiproliferative action of canagliflozin is observed in ECs isolated from both the venous and arterial circulation, and is partly due to the blockade of cyclin A expression. In addition, this study found that canagliflozin inhibits tube formation in cultured ECs and mouse aortic rings. Notably, these actions are specific for canagliflozin and not seen with other SGLT2 inhibitors. The ability of canagliflozin to exert these pleiotropic effects on EC function may contribute to both the adverse and salutary actions of this drug on cardiovascular function in T2DM patients. 


\section{ETHICS STATEMENT}

This study was approved by the institutional Animal Care-Use Committees of the University of Missouri and the Truman VA Hospital (Columbia, MO, USA) and performed in accordance with the National Research Council's Guide 152 for the Care and Use of Laboratory Animal.

\section{AUTHOR CONTRIBUTIONS}

GB, SMB, SBB, KP, LM-L, and WD participated in research design. $\mathrm{GB}, \mathrm{SMB}, \mathrm{ZD}$, and $\mathrm{KP}$ conducted experiments and

\section{REFERENCES}

Beckman, J. A., Creager, M. A., and Libby, P. (2002). Diabetes and atherosclerosis: epidemiology, pathophysiology, and management. JAMA 287, 2570-2581. doi: 10.1001/jama.287.19.2570

Birkeland, K. I., Jørgensen, M. E., Carstensen, B., Persson, F., Gulseth, H. L., Thuresson, M., et al. (2017). Cardiovascular mortality and morbidity in patients with type 2 diabetes following initiation of sodium-glucose cotransporter-2 inhibitors versus other glucose-lowering drugs (CVD-REAL Nordic): a multinational observational analysis. Lancet Diabetes Endocrinol. 5, 709-717. doi: 10.1016/S2213-8587(17)30258-9

Brand, T., Macha, S., Mattheus, M., Pinnetti, S., and Woerle, H. J. (2012). Pharmacokinetics of empagliflozin, a sodium glucose cotransporter-2 (SGLT-2) inhibitor, coadministered with sitagliptin in healthy volunteers. Adv. Ther. 29, 889-899. doi: 10.1007/s12325-012-0055-3

Brownlee, M. (2005). The pathobiology of diabetic complications. Diabetes 54, 1615-1625. doi: 10.2337/diabetes.54.6.1615

Camere, C., Pucelle, M., Negre-Salvayre, A., and Salvayre, R. (2017). Angiogenesis in atherosclerotic plaque. Redox Biol. 12, 18-34. doi: 10.1016/j. redox.2017.01.007

Chang, C. F., Liu, X. M., Peyton, K. J., and Durante, W. (2014). Heme oxygenase-1 counteracts contrast media-induced endothelial dysfunction. Biochem. Pharmacol. 87, 303-311. doi: 10.1016/j.bcp.2013.11.002

Creager, M. A., Luscher, T. F., Cosentino, F., and Beckman, J. A. (2003). Diabetes and vascular disease. Pathophysiology, clinical consequences, and medical therapy: part I. Circulation 108, 1527-1532. doi: 10.1161/01. CIR.0000091257.27563.32

Davies, M., Chatterjee, S., and Khunti, K. (2016). The treatment of type 2 diabetes in the presence of renal impairment: what should we know about the newer therapies. Clin. Pharm. 8, 61-81. doi: 10.2147/CPAA.S82008

De Vriese, A. S., Verbeuren, T. J., Van de Voorde, J., Lameire, N. H., and Vanhoutte, P. M. (2000). Endothelial dysfunction in diabetes. Br. J. Pharmacol. 130, 963-974. doi: 10.1038/sj.bjp.0703393

Devineni, D., Polidori, D., Curtin, C. R., Murphy, J., Wang, S.-S., Stieltjes, H., et al. (2015). Pharmacokinetics and pharmacodynamics of once-and twicedaily multiple-doses of canagliflozin, a selective inhibitor of sodium glucose co-transporter 2, in healthy participants. Int. J. Clin. Pharmacol. Ther. 53, 438-446. doi: 10.5414/CP202324

Durante, W., Sen, A. K., and Sunahara, F. A. (1988). Impairment of endotheliumdependent relaxation in aortae from spontaneously diabetic rats. Br. J. Pharmacol. 94, 463-468. doi: 10.1111/j.1476-5381.1988.tb11548.x

Elfeber, K., Kohler, A., Lutzenburg, M., Osswald, C., Galla, H. J., Witte, O. W., et al. (2004). Localization of the Na+- D-glucose cotransporter SGLT1 in the blood-brain barrier. Histochem. Cell Biol. 121, 201-207. doi: 10.1007/ s00418-004-0633-9

Fadini, G. P., and Avigari, A. (2017). SGLT2 inhibitors and amputations in the US FDA adverse event reporting system. Lancet Diabetes Endocrinol. 5, 680-681. doi: 10.1016/S2213-8587(17)30257-7

Fowler, M. J. (2008). Microvascular and macrovascular complications of diabetes. Clin. Diabetes 26, 77-82. doi: 10.2337/diaclin.26.2.77 performed data analysis. GB, SMB, SBB, LM-L, KP, and WD wrote or contributed to writing of the manuscript.

\section{FUNDING}

This work was supported by the American Diabetes Association [\#1-17-IBS-290 to WD], the Department of Veterans Affairs BLR\&D [IK2 BX002030 to SBB], and the National Institutes of Health [HL136386 to SBB and HL088105 to LM-L]. This work was also supported by the use of facilities and resources at the Harry S. Truman Memorial Veterans Hospital in Columbia, MO.

Fusco, S., Garasco, S., Corsonello, A., Vena, S., Mari, V., Gareri, P., et al. (2016). Medication-induced nephrotoxicity in older patients. Curr. Drug Metab. 17, 608-625. doi: 10.2174/1389200217666160406115959

Gu, K., Crowe, C. C., and Harris, M. I. (1998). Mortality in adults with and without diabetes in a national cohort of the U.S. population, 1971-1993. Diabetes Care 21, 1138-1145. doi: 10.2337/diacare.21.7.1138

Hagensen, M. K., Raarup, M. K., Mortensen, M. B., Thim, T., Nyengaard, J. R., Falk, E., et al. (2012). Circulating endothelial progenitor cells do not contribute to regeneration of endothelium after murine injury. Cardiovasc. Res. 93, 223-231. doi: $10.1093 / \mathrm{cvr} / \mathrm{cvr} 278$

Hawley, S. A., Ford, R. J., Smith, B. K., Gowans, G. J., Mancini, S. J., Pitt, R. D., et al. (2016). The $\mathrm{Na}^{+} /$glucose cotransporter inhibitor canagliflozin activates AMPK by inhibiting mitochondrial function and increasing cellular AMP levels. Diabetes 65, 2784-2794. doi: 10.2337/db16-0058

Huang, H., Vandekeere, S., Kalucka, J., Bierhansl, L., Zecchin, A., Bruning, U., et al. (2017). Role of glutamine and interlinked asparagine metabolism in vessel formation. EMBO J. 36, 2334-2352. doi: 10.15252/embj.201695518

Kaji, K., Nishimura, N., Seki, K., Sato, S., Saikawa, S., Nakanishi, K., et al. (2018). Sodium glucose cotransporter 2 inhibitor canagliflozin attenuates liver cancer cell growth and angiogenic activity by inhibiting glucose uptake. Int. J. Cancer 142, 1712-1722. doi: 10.1002/ijc.31193

Kalra, S. (2014). Sodium glucose co-transporter 2 (SGLT2) inhibitors: a review of their basic and clinical pharmacology. Diabetes Ther. 5, 355-366. doi: 10.1007/s13300-014-0089-4

Kasichayanula, S., Chang, M., Hasegawa, M., Liu, X., Yamahira, N., LaCreta, F. P., et al. (2011). Pharmacokinetics and pharmacodynamics of dapagliflozin, a novel selective inhibitor of sodium-glucose co-transporter type 2, in Japanese subjects without and with type 2 diabetes mellitus. Diabetes Obes. Metab. 13, 357-365. doi: 10.1111/j.1463-1326.2011.01359.x

Khoo, C. P., Micklem, K., and Watt, S. M. (2011). A comparison of methods for quantifying angiogenesis in the Matrigel assay in vitro. Tissue Eng. Part C. Methods 17, 895-906. doi: 10.1089/ten.tec.2011.0150

Kiefer, F. N., Munk, V. C., Humar, R., Dieterle, T., Landmann, L., and Battegay, E. J. (2004). A versatile in vitro assay for investigating angiogenesis of the heart. Exp. Cell Res. 300, 272-282. doi: 10.1016/j.yexcr.2004.06.032

Kim, B., Li, J., Jang, C., and Arany, Z. (2017). Glutamine fuels proliferation but not migration of endothelial cells. EMBO J. 36, 2321-2333. doi: 10.15252/ embj.201796436

Kurosaki, E., and Ogasawara, H. (2013). Ipragliflozin and other sodium-glucose cotransporter-2 (SGLT2) inhibitors in the treatment of type 2 diabetes: preclinical and clinical data. Pharmacol. Ther. 139, 51-59. doi: 10.1016/j. pharmthera.2013.04.003

Liang, Y., Arakawa, K., Ueta, K., Matsushita, Y., Kuriyama, C., Martin, T., et al. (2012). Effect of canagliflozin on renal threshold for glucose, glycemia, and body weight in normal and diabetic animal models. PLoS One 7:e30555. doi: 10.1371/journal.pone.0052269

Liu, X. M., Peyton, K. J., and Durante, W. (2013). Physiological cyclic strain promotes endothelial cell survival via the induction of heme oxygenase-1. Am. J. Physiol. Heart Circ. Physiol. 304, H1634-H1643. doi: 10.1152/ ajpheart.00872.2012 
Mancini, S. J., Boyd, D., Katwan, O. J., Strembitska, A., Almabrouk, T. A., Kennedy, S., et al. (2018). Canagliflozin inhibits interleukin-1 $\beta$-stimulated cytokine and chemokine secretion in vascular endothelial cells by AMPKactivated protein kinase-depenent and independent mechanisms. Sci. Rep. 8:5276. doi: 10.1038/s41598-018-23420-4

Meraji, S., Jayakody, L., Senaratne, M. P., Thomson, A. B., and Kappagoda, T. (1987). Endothelium-dependent relaxation in aorta of BB rat. Diabetes 36, 978-981. doi: 10.2337/diab.36.8.978

Nasiri-Ansari, N., Dimitriadis, G. K., Agrogiannis, G., Perrea, D., Kostakis, I. D., Kaltsas, G., et al. (2018). Canagliflozin attenutates the progression of atherosclerosis and inflammation process in APOE knockout mice. Cardiovasc. Diabetol. 17:106. doi: 10.1186/s12933-018-0749-1

Neal, B., Perkovic, V., Mahaffey, K. W., de Zeeuw, D., Fulcher, G., Erondu, N., et al. (2017). Canagliflozin and cardiovascular and renal events in type 2 diabetes. N. Engl. J. Med. 377, 644-657. doi: 10.1056/NEJMoa1611925

Pattanawongsa, A., Chau, N., Rowland, A., and Miners, J. O. (2015). Inhibition of human UDP-glucuronosyltransferase enzymes by canagliflozin and dapagliflozin: implications for drug-drug interactions. Drug Metab. Dispos. 43, 1468-1476. doi: 10.1124/dmd.115.065870

Peyton, K. J., Liu, X. M., Yu, Y., Yates, B., Behnammanesh, G., and Durante, W. (2018). Glutaminase-1 stimulates the proliferation, migration, and survival of human endothelial cells. Biochem. Pharmacol. 156, 204-214. doi: 10.1016/j. bcp.2018.08.032

Peyton, K. J., Liu, X. M., Yu, Y., Yates, B., and Durante, W. (2012). Activation of AMP-activated protein kinase inhibits the proliferation of human endothelial cells. J. Pharmacol. Exp. Ther. 342, 827-834. doi: 10.1124/jpet.112.194712

Rask-Madsen, C., and King, G. L. (2007). Mechanisms of disease: endothelial dysfunction in insulin resistance and diabetes. Nat. Clin. Pract. Endocrinol. Metab. 3:46-56. doi: 10.1038/ncpendmet0366

Resnick, H. E., and Howard, B. V. (2002). Diabetes and cardiovascular disease. Annu. Rev. Med. 53, 245-267. doi: 10.1146/annurev.med.53.082901.103904

Sajja, R. K., Prasad, S., and Cucullo, L. (2014). Impact of altered glycemia on blood-brain barrier endothelium: an in vitro study using the hCMEC/D3 cell line. Fluids Barrier CNS 11:8. doi: 10.1186/2045-8118-11-8

Santilli, S., Fiegel, V., Aldridge, D., and Knighton, D. (1992). The effect of diabetes on the proliferation of aortic endothelial cells. Ann. Vasc. Surg. 6, 503-510. doi: 10.1007/BF02000821

Scafoglio, C. R., Villegas, B., Abdelhady, G., Bailey, S. T., Liu, J., Shirali, A. S., et al. (2018). Sodium glucose transporter 2 is a diagnostic and therapeutic target for early stage lung adenocarcinoma. Sci. Transl. Med. 10:eaat5933. doi: $10.1126 /$ scitranslmed.aat5933

Secker, P. F., Beneke, S., Schlichenmaier, N., Delp, J., Gutbier, S., Leist, M., et al. (2018). Canagliflozin mediated dual inhibition of mitochondrial glutamate dehydrogenase and complex I: an off-target adverse effect. Cell Death Dis. 9:226. doi: 10.1038/s41419-018-0273-y

Sherman, S. E., Bell, G. I., Teoh, H., Al-Omran, M., Connelly, K. A., Bhatt, D. L., et al. (2018). Canagliflozin improves the recovery of blood flow in an experimental model of severe limb ischemia. JCC Basic Trans. Sci. 3, 327-329. doi: 10.1016/j.jacbts.2018.01.010

Simó, R., Carrasco, E., García-Ramírez, M., and Hernández, C. (2006). Angiogenic and antiangiogenic factors in proliferative diabetic retinopathy. Curr. Diabetes Rev. 2, 71-98. doi: 10.2174/157339906775473671

Taylor, K. S., Heneghan, C. J., Farmer, A. J., Fuller, A. M., Adler, A. I., Aronson, J. K., et al. (2013). All-cause and cardiovascular mortality in middle-aged people with type 2 diabetes compared with people without diabetes in a large U.K. primary care database. Diabetes Care 36, 2366-2371. doi: $10.2337 / \mathrm{dc} 12-1513$

Tumova, S., Kerimi, A., Porter, K. E., and Williamson, G. (2016). Transendothelial glucose transport is not restricted by extracellular hyperglycaemia. Vasc. Pharmacol. 87, 219-229. doi: 10.1016/j.vph.2016.11.001
Uthman, L., Baartscheer, A., Bleijlevens, B., Schumacher, C. A., Fiolet, J. W. T., and Koeman, A. (2018). Class effects of SGLT2 inhibitors in mouse cardiomyocytes and hearts: inhibition of $\mathrm{Na}+\mathrm{H}+$ exchanger, lowering cytosolic $\mathrm{Na}+$ and vasodilation. Diabetologia 61, 722-726. doi: 10.1007/ s00125-017-4509-7

Vane, J. R., Änggård, E. E., and Botting, R. M. (1990). Regulatory functions of the vascular endothelium. N. Engl. J. Med. 323, 27-36. doi: 10.1056/ NEJM199007053230106

Villani, L. A., Smith, B. K., Marcinko, K., Ford, R. J., Broadfield, L. A., Green, A. E., et al. (2016). The diabetes medication canagliflozin reduces cancer cell proliferation by inhibiting mitochondrial complex-I supported respiration. Mol. Metab. 5, 1048-1056. doi: 10.1016/j.molmet.2016.08.014

Virmani, R., Kolodgie, F. D., Burke, A. P., Finn, A. V., Gold, H. K., Tulenko, T. N., et al. (2005). Atherosclerotic plaque progression and vulnerability to rupture: angiogenesis as a source of intraplaque hemorrhage. Arterioscler. Thromb. Vasc. Biol. 25, 2054-2061. doi: 10.1161/01.ATV.0000178991.71605.18

Vrhovac, I., Balen Eror, D., Klessen, D., Burger, C., Greljak, D., Kraus, O., et al. (2015). Localizations of $\mathrm{Na}(+)$-D-glucose cotransporter SGLT1 and SGLT2 in human kidney and of SGLT1 in human small intestine, liver, lung, and heart. Pflugers Arch. 467, 1881-1898. doi: 10.1007/s00424-014-1619-7

Wang, H., Jiang, X., Yang, F., Chapman, G. B., Durante, W., Sibinga, N. E., et al. (2002). Cyclin A transcriptional suppression is the major mechanism mediating homocysteine-induced endothelial cell growth inhibition. Blood 99, 939-945. doi: 10.1182/blood.V99.3.939

Warren, C. M., Ziyad, S., Briot, A., Der, A., and Iruela-Arispe, M. L. (2014). A ligand-independent VEGFR2 signaling pathway limits angiogenic responses in diabetes. Sci. Signal. 7, ra1. doi: 10.1126/scisignal.2004235

Weihua, Z., Tsan, R., Huang, W. C., Wu, Q., Chiui, C. H., and Fidler, I. J. (2008). Survival of cancer cells is maintained by EGFR independent of its kinase activity. Cancer Cell 13, 385-393. doi: 10.1016/j.ccr.2008.03.015

Weinberg, R. A. (1995). The retinoblastoma protein and cell cycle control. Cell 81, 323-330. doi: 10.1016/0092-8674(95)90385-2

West, D. C., and Burbridge, M. F. (2009). “Three-dimensional in-vitro angiogenesis in the rat aortic ring model" in Angiogenesis protocols. 2nd Edn. eds. C. Murray, and S. Martin (New Jersey: Humana Press), 189-210.

Williams, S. B., Cusco, J. A., Roddy, M.-A., Johnstone, M. T., and Creager, M. A. (1996). Impaired nitric oxide-mediated vasodilation in patients with non-insulin-dependent diabetes mellitus. J. Am. Coll. Cardiol. 27, 567-574.

$\mathrm{Xu}$, J., and Zou, M. H. (2009). Molecular insights and therapeutic targets for diabetic endothelial dysfunction. Circulation 120, 1266-1286. doi: 10.1161/ CIRCULATIONAHA.108.835223

Yan, J., Tie, G., Park, B., Yan, Y., Nowicki, P. T., and Messina, L. M. (2009). Recovery from hind limb ischemia is less effective in type 2 than in type 1 diabetic mice: roles of endothelial nitric oxide synthase and endothelial progenitor cells. J. Vasc. Surg. 50, 1412-1422. doi: 10.1016/j.jvs.2009.08.007

Zinman, B., Wanner, C., Lachin, J. M., Fitchett, D., Bluhmki, E., Hantel, S., et al. (2015). Empagliflozin, cardiovascular outcomes, and mortality in type 2 diabetes. N. Engl. J. Med. 373, 2117-2128. doi: 10.1056/NEJMoa1504720

Conflict of Interest Statement: The authors declare that the research was conducted in the absence of any commercial or financial relationships that could be construed as a potential conflict of interest.

Copyright (c) 2019 Behnammanesh, Durante, Peyton, Martinez-Lemus, Brown, Bender and Durante. This is an open-access article distributed under the terms of the Creative Commons Attribution License (CC BY). The use, distribution or reproduction in other forums is permitted, provided the original author(s) and the copyright owner(s) are credited and that the original publication in this journal is cited, in accordance with accepted academic practice. No use, distribution or reproduction is permitted which does not comply with these terms. 